\title{
Exploring the Development of Financial Inclusion in the Context of Financial Technology
}

\author{
Ziyi Cheng* \\ Xi'an Beilin District Tie Yi High School, Xi'an 710000, Shaanxi Province, China
}

*Corresponding author: Ziyi Cheng, zyc2022ariana@163.com

\begin{abstract}
The concept of inclusive finance was proposed and promoted by the United Nations in 2005 with the main purpose of providing services for those who lack good financial services while promoting the economic growth of family enterprises and eliminating social poverty as well as inequality. With the innovation of financial technology and its application in the field of financial inclusion, the new inclusive finance has shown strong vitality and great prospects in recent years. It provides certain ideas and directions for the development of inclusive finance in the banking industry.
\end{abstract}

Keywords: Financial technology; Inclusive finance; Payment; Wealth management; Insurance

Publication date: August 2021; Online publication: August 30, 2021

\section{Concept, characteristics, and development trend of inclusive finance}

\subsection{Concept of inclusive finance}

Inclusive finance is an emerging concept that changes our perception of financial services. Its purpose is to provide financial services to those who lack good financial services, and its ultimate goal is to support the economic growth of enterprises and households, eliminate poverty and inequality, as well as include all those who need financial services so that everyone is able to receive appropriate financial services that match their needs ${ }^{[1]}$.

Inclusive finance is both a business concept and a social idea. As a business concept, inclusive finance expands the scale of financial markets where traditional finance stops. On the other hand, as a social idea, inclusive finance intends to serve those who cannot share the fruits of the mainstream economic growth, especially micro and small enterprises along with low-income groups in developing countries who cannot access banking services at the right price and in a timely manner.

In the "Plan for Promoting the Development of Inclusive Finance (2016-2020)," released by China, inclusive finance is defined based on the requirements of equal opportunities and the principle of commercial sustainability in providing appropriate and effective financial services at affordable costs to all social classes and groups in need of financial services. In view of the current development situation in China, the meaning of inclusive finance is based on the principles of equal opportunity, commercial sustainability, cost control, and targets groups in need of financial services through reasonable prices including small and medium-sized enterprises, individual entrepreneurs, low-income group, unemployed people, etc.; that is, provision of timely, convenient, and differentiated financial services in an effective, comprehensive, and sustainable manner.

\subsection{Characteristics of inclusive finance}

Inclusive finance requires four endogenous requirements which are accessibility, affordability, 
comprehensiveness, and commercial sustainability. Accessibility means that customers are able to obtain financial support anytime and anywhere according to their business needs with little time and space constraints, and to realize the perfection of financial service coverage. Affordability means that the price of financial services is widely acceptable for the service recipients. Comprehensiveness represents the comprehensiveness of the service targets of the financial services. Inclusive finance should not only serve those who have never received financial services, but it should improve the services for those customers who have not received comprehensive financial services while the service content should not only meet the basic needs, but it should also further improve the higher needs. Commercial sustainability implies that the inclusive financial policy cannot rely on government subsidies, but it should be financially self-sufficient and be a sustainable market-based business model.

\subsection{Development trend of inclusive finance}

Inclusive finance has been developing internationally for more than 40 years, yet the current development still cannot be considered perfect. For example, in the global context, microcredit currently has 150 million active customers and a loan size of about 45 billion to 60 billion dollars. According to calculations, the number of households in need of loans worldwide is about 600 million which currently covers only $25 \%$. In terms of loan penetration, it is expected that the total number of loans offered to households is currently only $20 \%$ of the size while $80 \%$ is still to be achieved. The world today is focusing a lot on financial inclusion, hoping for a comprehensive and groundbreaking development in 5 to 10 years. However, in terms of efficiency, it is hardly satisfactory that $70 \%$ to $80 \%$ of the population is still not covered after more than 40 years of development.

In the past, financial inclusion development has encountered insurmountable bottlenecks. The fundamental reason is that it is difficult for enterprises to realize commercial and social benefits. In order to realize commercial benefits, it would require higher prices and profits. The higher the interest rate on loans, the smaller the social benefits. It is difficult for low-income groups to pay exorbitant interest rates where the cost of credit is relatively high for low-income groups. In addition, traditional financial inclusion is usually expensive with regular and frequent customer visits; thus, to reach low-income vulnerable groups and offline high-density physical outlets, it is difficult to balance commercial and social benefits.

Now, experts in the field of inclusive finance around the world have a general consensus that the development of new types of inclusive finance needs to be established based on the development of financial technology. Only good application of financial technology can better solve the bottlenecks encountered by the traditional financial inclusion. Numerous scholars have used concepts such as artificial intelligence (AI), internet, means of communication, and terminal devices to study and predict some major developments in the future of inclusive finance; that is, from high contact to no contact. High contact means frequent docking with customers, which is a typical practice of traditional inclusive finance, but now there is no need to meet customers every day as new technology models, such as internet cell phones, can be used to dock customers. This new business model has a broad prospect, and its outstanding feature is that it can significantly enhance the speed and breadth of coverage while reducing costs ${ }^{[2]}$. Only through the use of financial technology, labor costs can be saved in time and the local and scattered population can be integrated more comprehensively to be lifted out of poverty along with small and micro enterprises in addition to solve the traditional financial inclusion through the improvement of digital information processing capability in the difficulty to solve the problem of credit collection.

In recent years, with the gradual application of digital technology, especially the internet in regard to banking, security, and insurance industries, it has largely increased the channels and means for traditional financial institutions to transmit information and conduct businesses, improved the efficiency of financial institutions' operations, as well as effectively expanded the coverage of financial services. The result of 
this organic combination of technological progress and traditional financial model is that the boundaries between the two are increasingly blurred where a new financial technology ecology is gradually forming. Financial innovation is not only the simple addition of digitalization and internet elements on top of traditional financial services, but it also includes many new financial products' design led by non-financial institutions and driven by technological innovations, which are highlighted in various fields such as payment, wealth management and insurance, etc. It is necessary to have an in-depth understanding and exploration of these financial technology-led financial inclusion practices.

\section{Impact of financial technology in the field of financial management on financial inclusion}

As a way to preserve and increase the value of wealth, financial management is favored by many investors. Along with the development of financial technology, wealth management is no longer just a simple as bank deposits, insurance, and securities, but both investment channels and investment methods have seen some brand-new changes. It is this series of new changes that greatly enhance the accessibility of financial services and implement the concept of financial inclusion ${ }^{[3]}$.

\subsection{Changes in the field of financial management driven by financial technology}

\subsubsection{Internet financial products}

The concept of internet financial products is different from that of traditional financial products. General bank financial management has an investment threshold of 50,000 yuan, while the investment threshold of micro financial management is only 0.01 yuan. The substantial reduction of the investment threshold makes it easier for the public to use financial management for asset allocation. Financial technology is well applied in internet financial products where they have various functions, such as electronic payment, transfer, and repayment, which are not available in traditional financial products. The balance is the most typical representative of this. The wide application of financial technology allows internet financial products to have diversified functions, which are naturally favored by investors.

\subsubsection{Digital asset allocation}

The application of financial technology makes the trend of intelligence prominent. The widespread application of big data technology and artificial intelligence promote the development of digital asset allocation while artificial wealth management begins to transform in the direction of intelligent investment advisor. Intelligent investment advisors are able to use computer technology, portfolio models, and other technical optimizations to screen portfolios which are optimal according to their customer's risk preference and asset allocation requirements, as well as continuously adjust and optimize them to create maximum return under the customer's given risk conditions. Digital asset allocation overcomes the emotional irrationality of human beings and reduces the investment risk brought by irrationality to a certain extent while intelligent investment advice expands the exclusive service that is originally belonged to high-networth clients to the general public. The promotion of digital asset allocation has greatly enhanced the convenience of public participation in financial activities. This is an important symbol of financial inclusion.

\subsubsection{Online lending platform}

The birth of online lending platforms is inseparable from the development of internet finance. Early online lending platforms existed only as information intermediaries where later on, the business gradually expanded, and internet financial products were also sold on online lending platforms. However, unlike the cooperation between balance of payments and Tianhong Fund, the internet financial products of online 
lending platforms are derived based on peer-to-peer (P2P) model, and online lending platforms complete the construction of investment portfolios internally, then put the funds out with the help of the platform itself, which enables the smooth flow of funds within the platform. As a new type of financial management, it has significantly improved the creditworthiness of individuals as well as small and micro enterprises, hence making it possible to solve the problem of difficult financing for small and micro enterprises to a certain extent. However, compared with the other two ways, the credit ratings of online lending platforms themselves are not high. Many internet financial products rely on the reputation of the internet site, such as Alibaba, Tencent, Jingdong, etc., while artificial intelligence investment advisors rely on the reputation of financial institutions, and these online lending platforms lack such reputation. Hence, once the P2P mines burst, it is difficult for investors to recover their losses, which is a problem in the current development of inclusive finance.

\subsection{A case of the practice of financial inclusion with BalancePay}

BalancePay, which is jointly developed by Alipay and Tianhong Fund, was launched in June 2013 as an internet financial product that provides value-added services to customers by using a third party as a payment platform. It adopts the $\mathrm{T}+0$ transaction system where the transaction amount is as low as 1 dollar and has the function to check daily incomes anytime and anywhere, which is not only fast and convenient, but also transparent and efficient. Customers would not only enjoy high investments and financial remunerations, but they are also able to make online and offline consumptions in their daily lives. This is a fund management tool which combines the concept of internet finance and inclusive finance.

As understood, BalancePay has shown strong vitality since its launch, which is concentrated in its rapid scale expansion with a total scale reaching 1.58 trillion yuan by the end of 2017 , almost doubling year-onyear. Meanwhile in 2017, subscriptions and redemptions amounted to 13.47 and 12.7 trillion yuan, respectively. Among all the domestic money market funds, BalancePay came out on top with its scale in the first place.

On May 27, 2017, it was announced for the first time that the limit for a single account would be lowered to 250,000 yuan from the previous 1 million yuan. On August 14 of the same year, the limit was lowered to 100,000 yuan, and on December 8, 2017, it was stipulated that the maximum amount of subscriptions in a single day should not exceed 20,000 yuan. On February 1, 2018, the daily limit was set at 9:00 a.m. According to BalancePay's financial report, its fund size shrank by 190.5 billion yuan in the fourth quarter of this year compared with the previous quarter, while the size of other funds in the pool increased slightly by 183.1 billion yuan with its total size decreased by 7.3 billion yuan as of the beginning of 2019 and standing at 1.92 trillion yuan.

BalancePay follows the concept of both, financial inclusion and serving the public. It draws on the advantages of internet finance and combines the two perfectly. At present, BalancePay, in today's situation, not only limits the amount of individual user accounts to maintain stability but also actively develops the rural market and expands the scale of users, insisting on following the concept of inclusive finance. Since its launch, it has attracted a total of 474 million purchases of which individual investors account for $99.94 \%$, the average share held by individual investors is 3329.57 yuan, the average age of investors is 29 years old with a normal distribution trend, and geographically, it basically covers all the 2,749 administrative counties in China. BalancePay has been continuously improved since its launch, and now it has met most of the transaction needs of its users. For example, online and offline shopping, financial management, life payment, money transfer, and so on.

The concept of inclusive finance is the key factor for BalancePay to become stronger and bigger. Firstly, BalancePay combines the positioning of inclusive finance with the advantages of internet finance, which not only lowers the threshold so that the urban population can also participate but also makes it convenient 
and fast. This innovative combination has formed its own unique advantages. Second, the inclusive positioning provides a stable and predictable cash flow for BalancePay. BalancePay users range from highincome groups to urban residents, which is quite a wide distribution. Moreover, the transaction needs are too scattered, and the single amount is generally small, but the vast majority of transactions are based on living needs, and after various cash flows are offset, the remaining net cash flow is rather stable. Finally, the positioning of inclusive finance provides BalancePay with more product value and data support in many aspects. On the one hand, BalancePay has both the wealth management and consumption account functions so it is able to continue to explore richer product values along these two lines. On the other hand, the consumption and investment behaviors triggered by customers in their daily lives are of great significance for analyzing customers' risk tolerance, consumption preference, and investment preference.

In the future, BalancePay will continue to develop steadily: firstly, it will continue to lower the upper limit of individual customers' holdings to maintain stability; secondly, it will continue to expand in lower tier cities and rural markets so that it can serve more people who usually have no or little access to financial products to better implement the concept of financial inclusion. At present, broadband, mobile network, computers, and smartphones are quite common in rural areas, hence meeting the needs of BalancePay. At present, bank branches in rural areas are generally distributed in towns or cities where the distance from their residences is the main reason why rural residents are rather hesitant to manage their money. BalancePay can effectively solve this problem by relying on the network and its convenience, which is an important direction and area for the future development of BalancePay.

\subsection{Future development direction of the financial management field}

In the future, the development direction of the financial management field can be further developed in rural areas. The financial ecology of rural areas is completely different from that of urban areas where private lending is extremely prevalent and rural credit unions are not fully functional in providing financial services. In order to further encourage financial technology to spread to rural areas, it is necessary to start from the living habits of the people there. Rural people are more concerned about the existence of paper money, hence lowering the financial threshold of rural credit unions so that farmers can use more of their free money to invest is the first step at the moment. At the same time, penetrating the use of paperless payment platforms, such as WeChat and Alipay, is also an important aspect in promoting the application of financial technology to rural finance. The two-pronged approach to rural financial management is likely to undergo a qualitative transformation.

\section{Impact of fintech on financial inclusion in the insurance field}

\subsection{Third-party internet insurance platform}

\subsubsection{Introduction of third-party internet insurance platform}

A third-party internet insurance platform refers to a network platform, such as a third-party insurance intermediary or a part-time agency industry website that provides mature network technical support services for traditional insurance companies to sell their insurance products. The platform has the characteristics of fairness, neutrality, scale effect, specialization, and strong service. It is an efficient information exchange center between insurance companies and customers.

\subsubsection{A case of Ant Financial Services' practice of financial inclusion}

Among all the third-party internet insurance platforms, the most representative one is Ant Financial Services (Ant Financial Services Group). Ant Financial Services, which was officially established in 2014, originated from Alipay and it aims to provide inclusive financial services to the world. Ant Financial 
Services is committed to build an open ecosystem, accelerate the process of "Internet + " for financial institutions and partners on the basis of Alipay as well as other products and services, provide inclusive financial services for small and micro enterprises as well as the largest number of people, in addition to rely on big data, cloud computing, AI, and other technologies to enable users to have equal access to financial services, which not only broadens the scope of inclusive financial services, but also improves the efficiency of services.

Based on the scenario of internet consumption, Ant Financial Services had launched various kinds of consumer insurance such as return shipping insurance, price insurance, and quality assurance insurance. For example, return shipping insurance is inexpensive; generally, only about 1 yuan, but it effectively solves the problem of bearing shipping costs during shopping returns on Taobao and other e-commerce platforms. This changes the impression that insurance is low-frequency and large in the eyes of the public, making it possible for the public to shop online with a peace of mind in addition to vigorously promoting the development of e-commerce. On the Double 11 day in 2017, as of 12 noon, the return shipping insurance exceeded 187 million units: exceeding the total amount of the whole day during the Double 11 in 2016, as of 2:00 p.m. It reached 208 million units with a premium scale of over 187.2 million yuan, which was sufficient to illustrate its hot degree. Another example is that Ant Financial Services launched an innovative insurance product called "National Insurance - Lifetime Pension" in 2018, which completely solved the pain of the public needing to spend hundreds of dollars per month or tens of thousands of dollars per year to buy traditional pension insurance. The "Universal Insurance" begins with only 1 yuan without any limit to the amount, number of times of investment, and payment period so people can flexibly make their own insurance plan according to their situation. The design of these insurance products by Ant Financial Services reflects its original intention of universal coverage.

In the digital era, the only way for a third-party internet insurance platform to accurately grasp future trends, make up for shortcomings, enhance its advantages, and achieve long-term development is to have the ability to perceive, analyze, and maintain customers' needs as well as their changes, supply demanddriven products and services while building a solid foundation of information technology (IT) research and development (R\&D) platform support.

\subsection{Professional internet insurance company}

\subsubsection{Introduction of professional internet insurance company}

A professional internet insurance company refers to a professional insurance company that has obtained the insurance business license from China Banking and Insurance Regulatory Commission (CBIRC) and specializes in online insurance business. The advantage of online platform is that it can efficiently provide comprehensive, integrated, and targeted special services even when the service audience is wider compared with the traditional platform.

The development of China's internet insurance started late, and there are more than 50 insurance companies involved in the internet business, which has to a certain extent promoted the change and innovation of China's insurance industry with four approved licensees, namely Zhong An Insurance, Taikang Online, Anxin Insurance, and Yi An Insurance.

\subsubsection{A case of Taikang Online's practice of financial inclusion}

China's internet insurance has also made some attempts in the field of inclusive finance, but the effect is not obvious enough in which it is related to the underdeveloped insurance market and weak basic financial services in poor areas. Among them, Taikang Online Property Insurance Co. Ltd. won the Beijing Financial Forum Inclusive Finance Practice Award in 2017. As the first internet insurance company initiated by 
Taikang Life, some of its innovative ideas are worthy of reference.

In November 2017, Taikang Online and Tencent Weibo launched the "Micro Medicare," which is a medical insurance product. Its advantage is that it has a deposit advance function, which pays $100 \%$ for 100 kinds of serious illnesses and advance hospital deposits on behalf of the patients, thus relieving the pressure of treating patients with acute and serious illnesses as well as improving the efficiency of medical treatment. In addition, "Micro Medicare" offers a fast, flash, and direct claims service. This product not only breaks the limits of traditional medical insurance reimbursement, but it also guarantees timely treatment of various types of high morbidity diseases, which is truly beneficial to the public.

Since its establishment, Taikang Online has been striving to implement the concept of financial inclusion, and its online products, such as "Medical Insurance for Elderly Malignant Tumors" and "Hospitalization Insurance," have helped to solve the existing medical difficulties of individuals and families in China. The products have been formulated from the perspective of people's needs for life protection and the continuous enrichment of the connotation of inclusive spirit. In addition to that, Taikang Online is also considering the development of exclusive products for migrant workers and left-behind children in rural and remote areas.

In the future, new technologies, such as big data, can be used to pinpoint the needs of public and rural areas, as well as innovate and improve new businesses. On the other hand, the convenience of the internet can be used to create an "online + offline" sales model and further accelerate the exploration of the "service before sales" business model to provide diversified services in terms of clothing, food, housing, and transportation for the public.

\section{Conclusion}

From the above discussion on the inclusive finance based on fintech, it can be easily appreciated that the new inclusive finance has great prospects and significant socio-economic values. First, from the perspective of economics, there has been a commitment to find a suitable fulcrum between social equity and social efficiency as it is difficult to achieve a balanced development of these two in the society due to various restrictions of the traditional financial inclusion. However, one can see the hope and trend of future development in the new inclusive finance practice, which can achieve the unity of equity and efficiency by reducing costs while expanding service space through financial technology. Second, the new inclusive finance drives the improvement, expansion, and cost reduction of financial services where the beneficiaries do not only include those once marginalized groups but instead, all market participants. Third, the new inclusive finance has driven the reform of the entire financial system in the past. Fintech is no longer simply a tool used for the financial framework, but in turn has profoundly influenced financial foundations where for example, products such as BalancePay have successfully achieved a certain degree of competition with banks and accelerated the marketization of interest rates. It is expected that fintech-based financial inclusion would be able to develop better in the future and truly realize the original purpose of the idea of financial inclusion in a thorough and comprehensive way.

\section{Disclosure statement}

The author declares that there is no conflict of interest.

\section{References}

[1] Luo S, Chen X, Yao Y, 2016, Research on Poverty Reduction Effect of Inclusive Financial Development in China. Contemp Econ Res, 12: 84-93.

[2] Hasan MM, Lu Y, Mahmud A, 2020, Regional Development of China's Inclusive Finance through 
Financial Technology. SAGE Open, 10(1).

[3] Zhang M, Yang J, 2018, Research on Financial Technology and Inclusive Finance Development. Advances in Social Science, Education and Humanities Research, 294: 66-71. 